\title{
Monitoring Treatment of Congenital Hypothyroidism by Highly Sensitive Immunoradiometric Assay for Thyroid Stimulating Hormone
}

\author{
Hirokazu SATO, Hiroaki INOMATA, Nozomu SASAKI, Hiroo NIIMI \\ AND HIRONORI NAKAJIMA \\ Department of Pediatrics, School of Medicine, Chiba University, \\ Chiba 280, Japan
}

\begin{abstract}
To assess the clinical value of a sensitive immunoradiometric assay for TSH (IRMA-TSH), serum IRMA-TSH levels were compared with those of a radioimmunoassay (RIA-TSH) in twenty-eight patients with congenital hypothyroidism. Among 144 samples taken from them, 44 samples showed undetectable RIA-TSH, while only 10 samples were undetectable by IRMA-TSH. In two patients prospectively followed, RIA-TSH levels were undetectable when serum T3 and T4 were normal. IRMA-TSH levels, however, were detectable when serum T4 levels were elevated or normal.

The basal RIA- and IRMA-TSH levels in 4 groups (22 patients) were compared and classified according to the TSH response to TRH. The RIATSH levels were undetectable in any in group $1(n=7$; absent response) or group $2(\mathrm{n}=5$; low response). At the same time, IRMA-TSH levels were undetectable in only three patients in group 1 . In group $3(n=16$; normal response), RIA-TSH levels were undetectable in three, whereas IRMA-TSH levels were detectable in all. The IRMA- and RIA-TSH levels rose in all in group $4(\mathrm{n}=15$; exaggerated response).

These results suggest that the serum basal IRMA-TSH levels indicate the responsiveness of TSH to TRH more accurately than basal serum RIA-TSH levels. Therefore, it was concluded that IRMA-TSH may obviate the need for a TRH test and simplify the evaluation of adequate dosage in patients with congenital hypothyroidism during thyroxine treatment.
\end{abstract}

Adequate replacement therapy with thyroid hormone is mandatory in patients with congenital hypothyroidism detected by neonatal screening. The appropriate dose of thyroid hormones has been assessed by clinical findings, serum thyroid hormones

Received December 15, 1986

Correspondence: Hirokazu Sato, Department of Pediatrics, School of Medicine, Chiba University, 1-8-1 Inohana, Chiba 280, Japan and serum TSH levels. An undetectable serum TSH level with increased thyroxine (T4) may indicate an overdose of 1-T4. However, the evaluation of undetectable TSH has remained controversial, because of the limited sensitivity of TSH by radioimmunoassay (RIA-TSH). Thus, an overdose has been assessed by the TSH response to TRH as well as serum thyroid hormone levels. 
The development of a sensitive immunoradiometric assay for TSH (IRMATSH), which is claimed to detect TSH concentrations as low as $0.1 \mathrm{mU} / 1$, raised the possibility that this assay might discriminate between euthyroid and overt or subclinical hyperthyroid patients without TRH tests. Furthermore, the clinical value of IRMATSH has been demonstrated in adult patients (Seth et al., 1984; Kerr et al., 1984 ; Caldwell et al., 1985; McBride et al., 1985).

In this study, we have attempted to investigate the clinical advantages of IRMATSH measurement in children with congenital hypothyroidism on replacement therapy.

\section{Materials and Methods}

Twenty-eight patients with congenital primary hypothyroidism disclosed by neonatal screening, ranging in age from one month to seven years, were studied during replacement therapy with 1T4. All patients had been referred to Chiba University Hospital for further examination, and their clinical status was assesed periodically there. The therapy was started when the patient was about a month old, and the duration of the therapy until the end of the present study was $4.0 \pm 1.9$ years $(m \pm S D)$. At the end of this study, all patients were clinically euthyroid and their growth rate, skeletal maturation and neuropsychological development were normal. During the study, serum T4 levels were kept at high normal levels, and the replacement dose was $2.9-6.6 \mu \mathrm{g} / \mathrm{kg}$ body weight/day in patients aged two to seven years and $3.9-10 \mu \mathrm{g} / \mathrm{kg} /$ day in patients from one to 16 months old. A single daily dose of 1-T4 was administered in the morning, and blood was taken at six to eight hours later (between 1400 and 1600) for serum thyroid hormone and TSH measurement.

The serum samples were stored at $-20^{\circ} \mathrm{C}$ before assay. Serum triiodothyronine (T3), T4 and RIA-TSH concentrations were determined by RIA (T3 and T4: Daiichi, Tokyo, Japan; TSH : Eiken, Tokyo, Japan). The normal values for serum T3, T4 and RIA-TSH below one year of age and between two and seven years were as follows : $\mathrm{T} 3,2.1-3.4 \mathrm{nM} / 1$ and $1.9-3.4 \mathrm{nM} / 1$; T4,
94-181 nM/1 and 75-161 nM/1; RIA-TSH, lower than $11.2 \mathrm{mU} / 1$ and lower than $5.4 \mathrm{mU} / 1$, respectively. The detection limit of RIA-TSH was $1.2 \mathrm{mU} / \mathrm{l}$, with values lower than this deemed undetectable. The interassay coefficients of variation for T3, T4 and RIA-TSH were less than $10 \%$.

IRMA-TSH levels were measured by the Boots-Celltech Sucrosep TSH IRMA (Booths Celltech Sucrosep TSH IRMA, Booths Celltech Diagnostic Limited). The IRMA-TSH had a substantially lower limit of detection at $0.1 \mathrm{mU} / 1$ (lower than the value termed as undetectable) in this study. Serum IRMA-TSH concentrations were also measured in 54 normal children, aged one month to 14 years, and 13 untreated patients with Graves' disease aged six to 14 years.

The serum TSH response to TRH was ascertained in 22 patients at the age of two to seven years during 1-T4 treatment and 43 tests were performed. Serum TSH was measured before and at 30 minutes after the intravenous administration of TRH, $10 \mu \mathrm{g} / \mathrm{kg}$ body weight.

According to the RIA-TSH levels after TRH administration, the results of TRH tests were divided into four groups : group $1: \mathrm{n}=7$, absent response of TSH (RIA-TSH level after TRH: undetectable), group 2: $n=5$, low response (below $7 \mathrm{mU} / \mathrm{l}$ ), group $3: \mathrm{n}=16$, normal response (7-34 mU/1), group 4: $n=15$, and exaggerated response (above $34 \mathrm{mU} / \mathrm{l}$ ).

Serum RIA-TSH, IRMA-TSH, T3 and T4 levels were measured serially in two of the 28 patients to compare the basal IRMA-TSH level with that of RIA-TSH. The figures were given as $\mathrm{m} \pm \mathbf{S D}$, and statistical analysis was done by Student's $t$-test.

\section{Results}

\section{Normal serum IRMA-TSH concentrations}

The normal range of serum IRMA-TSH concentrations in children less than and more than one year of age was 1.0-10.5 $\mathrm{mU} / 1$ and $0.6-5.3 \mathrm{mU} / 1$, respectively (Fig. 1) and the difference between them was significant $(\mathrm{P}<0.01)$. No age-dependent differences in IMRA-TSH concentrations were observed among children in either group. There were no nomal children whose IMRA- 


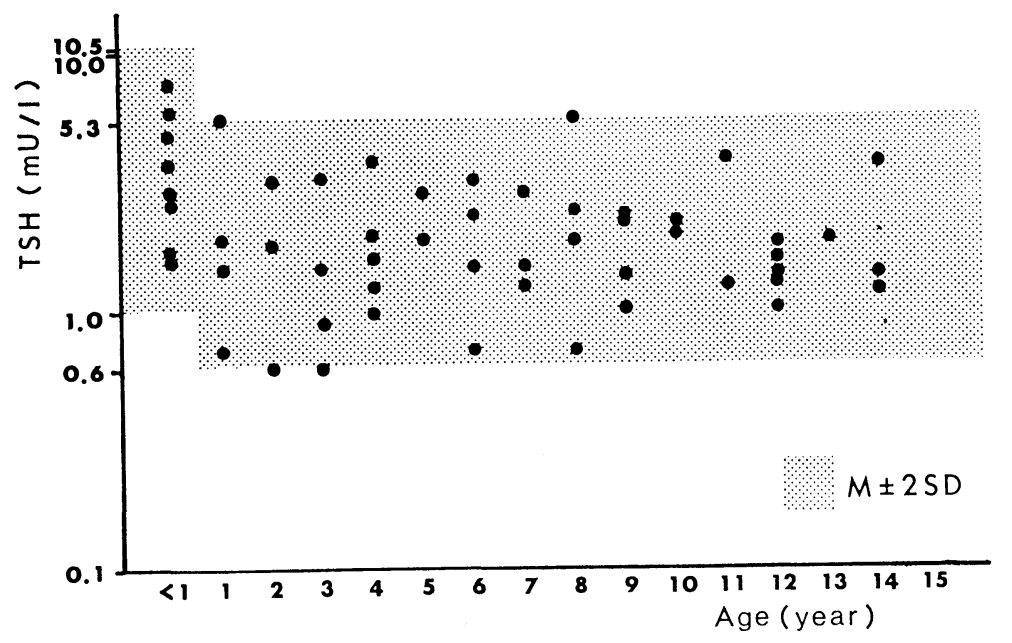

Fig. 1. Serum TSH concentrations measured by IRMA in normal children. Shaded area shows normal range (mean $\pm 2 S D$ ). Normal range in infants less than one year old is significantly higher than in children aged $1-15(\mathrm{P}<$ 0.01)

Case 1

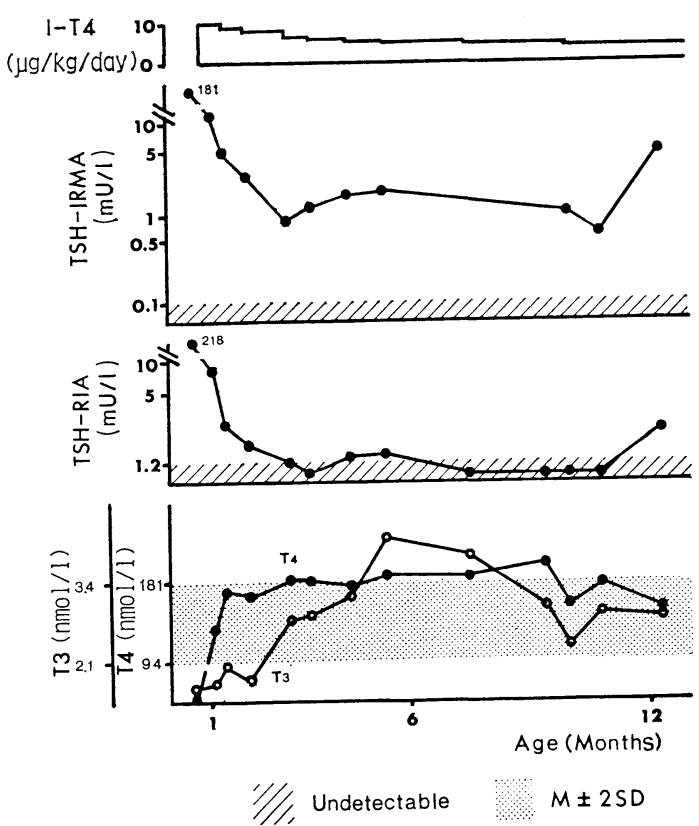

Fig. 2. Serum total thyroxine, triiodothyronine, IRMA- and RIA-TSH cocentrations in Case 1 .

Shaded area shows the undetectable levels of both RIA- and IRMA-TSH, and dotted area shows normal range.

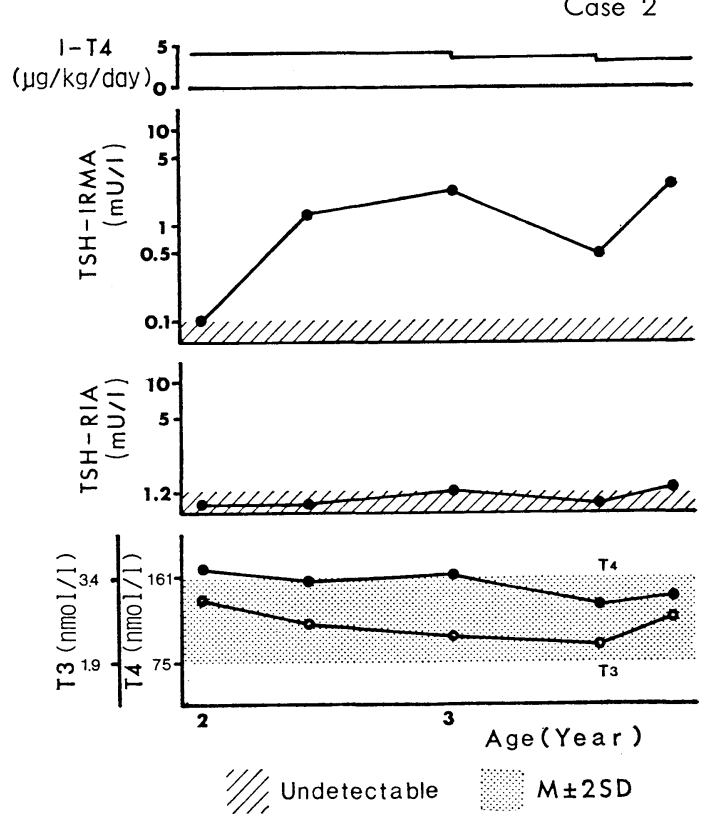

Fig. 3. Serum total thyroxine, triiodothyronine, IRMA- and RIA-TSH concentrations in Case 2. Shaded area and dotted area are as in Fig. 2. 
TSH concentrations were undetectable by this assay. However, in untreated patients with hyperthyroidism, serum IRMA-TSH levels were undetectable.

Comparison of IRMA- and RIA-TSH levels in patients on replacement therapy

The RIA-TSH levels were undetectable when serum T4 and T3 were normal or raised at several points in two patients (Fig. 2 and 3), whereas serum IRMA-TSH levels were continuously within the normal range at the same points.

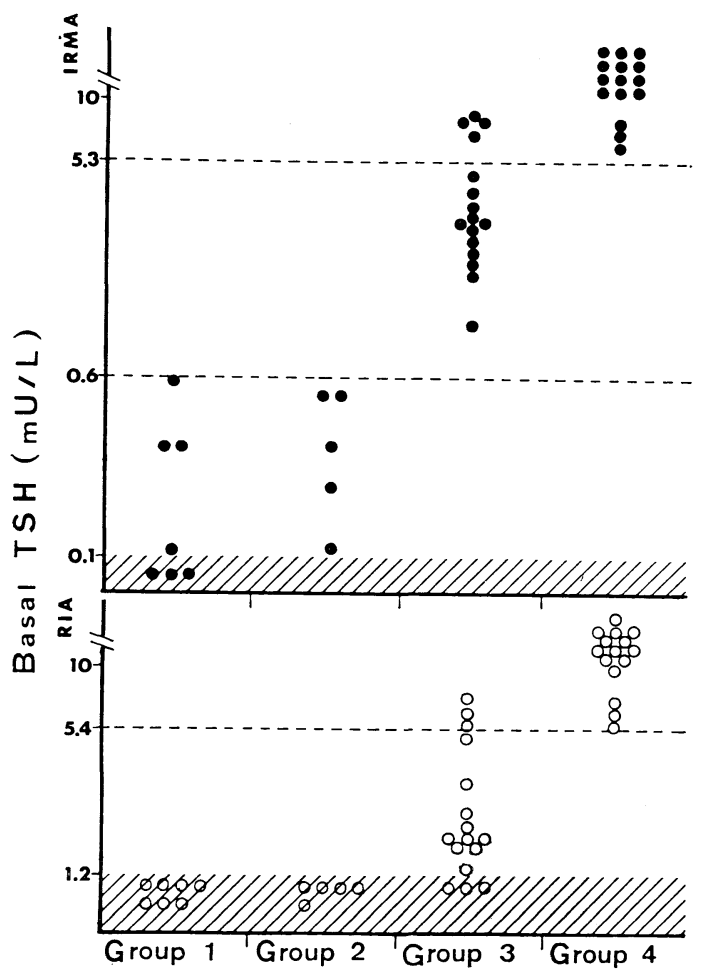

Fig. 4. Comparison of basal RIA- $(\bigcirc)$ and IRMA- (O) levels among four group. The results of the TRH test were divided into four groups according to the RIA-TSH levels after TRH administration as described in Materials and Methods.

Shaded area is as in Fig. 2. The areas between the broken lines in IRMA-TSH and lower than the broken line in RIA-TSH indicate normal ranges.
The serum IRMA- and RIA-TSH concentrations were measured in 144 samples from the 28 patients. Serum RIA-TSH concentrations of 46 samples were undetectable, whereas IRMA-TSH levels were undetectable in only 10 of them. Half of the remaining samples showed subnormal and the other half normal IRMA-TSH levels.

Comparison of basal serum RIA-TSH and IRMA-TSH concentrations among four groups

The serum basal RIA-TSH levels were

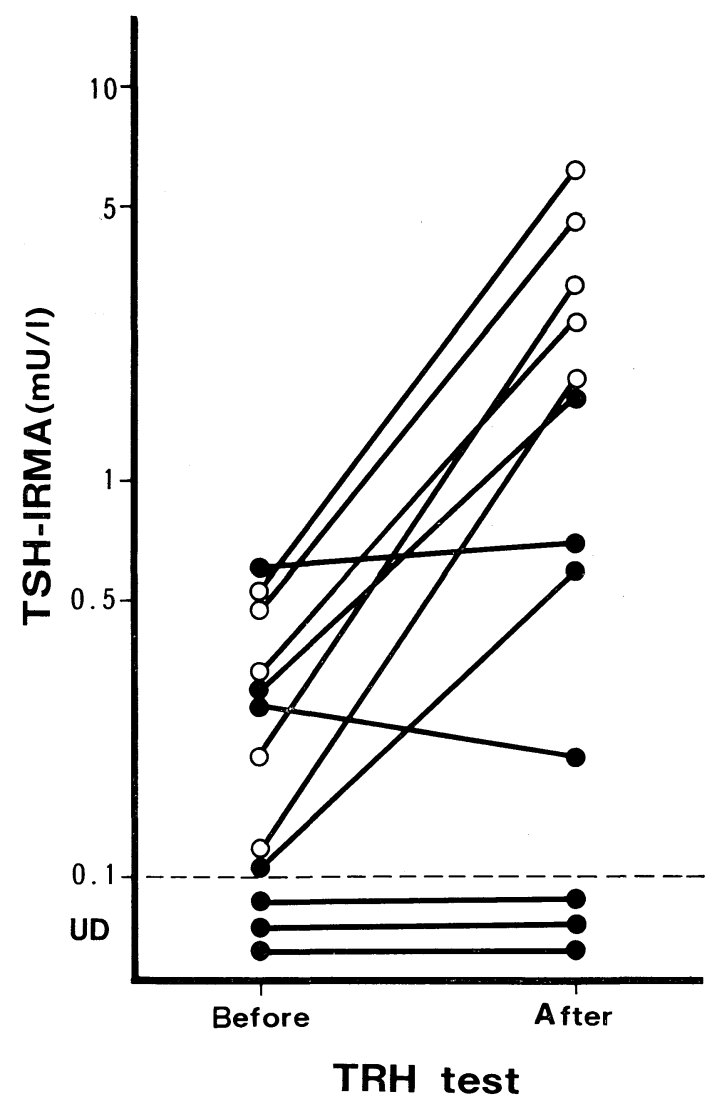

Fig. 5. The response of serum IRMA-TSI concentrations after TRH administration in patients whose basal IRMA-TSH levels were below normal (lower than $0.6 \mathrm{mU} / 1$.)

The circles show the absent (O) and low (○) responses of RIA-TSH. Broken line indicates limits of detection $(0.1 \mathrm{mU} / 1)$ and U. D. indicates undetectable. 
all undetectable in groups 1 and 2, whereas the basal IRMA-TSH level was undetectable in only three in group 1 and was between 0.1 and $0.6 \mathrm{mU} / 1$ in the other four in group 1 and all cases in group 2 (Fig. 4). In group 3, RIA-TSH levels were undetectable in three, in the detectable normal range in 10 and elevated in three. On the other hand, serum IRMA-TSH levels were normal in 12 and elevated in four, with none showing IRMA-TSH levels that were lower than normal. The IRMA- and RIATSH levels were all elevated in group 4.

Serum IRMA-TSH concentrations after administration of TRH in patients with low basal IRMA-TSH concentrations

TRH stimulated IRMA-TSH concentrations were still undetectable in three patients. The serum IRMA-TSH levels rose significantly from $0.3 \pm 0.2 \mathrm{mU} / 1$ to $2.3 \pm 2.0$ $\mathrm{mU} / 1$ in nine patients $(\mathrm{P}<0.01)$ (Fig. 5).

\section{Discussion}

The appropriate dose for replacement therapy with 1-T4 in patients with congenital hypothyroidism has been assessed by serum basal TSH or TSH responsiveness to TRH as well as serum thyroid hormones levels. However, an undetectable TSH level in RIA might not necessarily indicate a hyperthyroid state, since the detection limit for TSH in RIA is $1-2 \mathrm{mU} / 1$, and some normal children still have undetectable serum basal RIATSH. On the other hand, the BootsCelltech Sucrosep IRMA has been reported to be sensitive enough to discriminate between a normal condition and hyperthyroidism in adults (Alexander et al., 1984). It uses a combination of two different monoclonal antibodies, each of which is specific for a different epitope on the TSH molecule. The specificity derives from binding of two monoclonal antibodies on a different epitope of the TSH molecule.
We have shown the normal basal serum TSH values obtained by IRMA from infancy to adolescence. There have been no other reports on the normal IRMA-TSH levels in normal children. The results made it clear that the TSH concentrations below a year of age were significantly higher than the values in children aged one to 15 . This difference suggests the presence of an immature feedback mechanism in the thyroid axis, especially in early infancy (Oddie et al., 1977). The normal range in children more than a year old $(0.6-5.3 \mathrm{mU} / 1)$ was almost equal to that in adults (Alexander et al., 1984 ; Durham, 1985 ; McBride et al., 1985). The basal TSH concentration in normal children detected by IRMA was measurable in a detectable range. In contrast to this, undetectable IRMA-TSH concentrations have been seen in normal adults (Caldwell and Toft., 1984; Semple et al., 1985). This difference may indicate a decrease in serum TSH with age. Further studies are anticipated.

In a longitudinal investigation of two patients, the basal RIA-TSH levels continued to be undetectable when serum T4 levels were within the normal range. On the other hand, the basal IRMA-TSH levels were still continuously detectable even when serum T4 levels were slightly elevated. It is well known that serum free and total T4 levels may be elevated in clinically euthyroid patients during replacement therapy (Pearce et al., 1984 ; Mardell et al., 1985). Schultz et al. reported that the threshold for thyrotropin suppression rose in congenital hypothyroidism (Schultz et al., 1980). The present results showed that these two patients received an adequate dose of 1-T4, and the serum IRMA-TSH levels were preferred over RIA-TSH in assessing the thyroid status appropriately and in discriminating between the euthyroid and subclinical hyperthyroid state. A sufficient replacement dose of 1-T4 may be necessary to maintain its serum level at a high normal or a slightly raised 
level, since it has been shown that serum T4 is at least as important as T3 in controlling pituitary TSH release (Silva et al., 1977 ; Crantz et al., 1980 ; Larsen., 1982 ; Focarile et al., 1984 ; Mardell et al., 1985).

In the present study, many patients with undetectable levels of basal RIA-TSH showed low or normal response of RIATSH to TRH. On the other hand, all three patients with undetectable levels of basal IRMA-TSH showed no RIA-TSH response to TRH. Thus, the basal IRMA-TSH levels were more correlated with the RIATSH responsiveness to TRH than the basal RIA-TSH levels. Moreover, only these three patients with undetectable basal IRMA-TSH levels showed undetectable IRMA-TSH levels after TRH administration in patients who showed low response or no response of RIATSH to TRH. Thus, the undetectable IRMATSH levels showed complete suppression of TSH. Consequently, our findings suggest that it may no longer be necessary to perform the TRH test in patients with congenital primary hypothyroidism receiving thyroxine therapy in assessing the replacement dose, similar to those not receiving thyroxine (Seth et al., 1984; Kerr et al., 1984 ; McBride et al., 1985). The clinical assessment and measurements of serum thyroid hormone concentrations and basal TSH concentration by IRMA give sufficient information. The elevated serum thyroid hormones and undetectable IRMA-TSH concentrations suggest the advisability of a decrease in the replacement dose of 1-T4 in children with congenital hypothyroidism, as in adult patients taking exogenous thyroxine (McBride et al., 1985; Mardell et al., 1985).

We conclude that the highly sensitive IRMA is helpful in the assessment of thyroid function in children and will become a useful tool in the evaluation of equivocal patients with congenital hypothyroidism on replacement therapy.

\section{Acknowledgements}

We are most grateful to Mr. M. Okabe, Mr. Y. Kobayashi, and Mr. K. Akaishi of the Special Reference Laboratory Ltd. for their help in the present study.

\section{References}

Alexander, W. D., D. J. Kerr and M. M. Ferguson (1984). First-line test of thyroid function. Lancet ii, 647-647.

Caldwell, G. and A. D. Toft (1984). First-line test of thyroid function. Lancet ii, 1162-1162.

Caldwell, G., H. A. Kellet, S. M. Gow, G. J. Beckett, V. M. Sweeting, J. Seth and A. D. Toft (1985). A new strategy for thyroid function testing. Lancet ii, 1117-1119.

Crantz, F. R. and P. R. Larsen (1980). Rapid thyroxine to 3, 5, 3'-triiodothyronine conversion and nuclear 3,5, 3'-triiodothyronine binding in rat cerebral cortex and cerebellum. J. Clin. Invest. 65, 935-938.

Durham, A. P. (1985). The upper limit of normal for thyrotropin is 3 or $4 \mathrm{~m} \mathrm{U/1}$. Clin. Chem. 31, 296-298.

Focarile, F., G. F. Rondanini, A. Bollati, A. Bartolucci and G. Chiumello (1984). Free thyroid hormones in evaluating persistently elevated thyrotropin levels in children with congenital hypothyroidism on replacement therapy. J. Clin. Endocrinol. Metab. 59, 12111214.

Kerr, D. J. and W. D. Alexander (1984). Is the TRH test usually unnecessary? Lancet ii, 1161 $-1162$.

Larsen, P. R. (1982). Thyroid-pituitary interaction: Feedback regulation of thyrotropin secretion by thyroid hormones. N. Engl. J. Med. 306, 23-32.

Mardell, R. J., T. R. Gamlen and M. R. Winton (1985). High sensitivity assay of thyroid stimulating hormone in patients receiving thyroxine for primary hypothyroidism and thyroid carcinoma. Br. Med. J. 290, 355-356.

McBride, J. H., R. V. Thibeault and D. O. Rodgerson (1985). Thyrotropin as measured by a sensitive immunoradiometric assay. Clin. Chem. 31, 1865-1867.

Oddie, T. H., D. A. Fisher, B. Bernard and R. W. 
Lam (1977). Thyroid function at birth in infants of 35 to 45 weeks' gestation. J. Pediatr. 90, 803-806.

Pearce, C. J. and R. L. Himsworth (1984). Total and free thyroid hormone concentrations in patients receiving maintenance replacement treatment with thyroxine. $B r . M e d . J .288$, 693-695.

Schultz, R. M., M. S. Glassman and M. H. Macgillivray (1980). Elevated threshold for thyrotropin suppression in congenital hypothyroidism. Am. J. Dis. Child. 134, 19-20.

Semple, C. G., S. D. Slater, A. M. Reid and
A. C. A. Glen (1985). A sensitive immunoradiometric assay for serum thyroid stimulating hormone. Br. Med. J. 290, 69-70.

Seth, J., H. A. Kellett, G. Caldwell, V. M. Sweeting, G. J. Beckett, S. M. Gow and A. D. Toft (1984). A sensitive immunoradiometric assay for serum thyroid stimulating hormone: a replacement for the thyrotrophin releasing hormone test? Br. Med. J. 289, 1334-1336. Silva, J. E. and P. R. Larsen (1977). Pituitary nuclearin 3, 5, 3'-triiodothyronine and thyrotropin secretion: an explanation for the effects of thyroxine. Science 198. 617-620. 